\title{
LEVANTAMENTO DE EPÍFITAS NA ARBORIZAÇÃO URBANA DO MUNICÍPIO DE LUIZIANA - PARANÁ
}

\author{
DETERMINATION OF EPIPHYTES IN URBAN AFFORESTATION IN THE CITY OF \\ LUIZIANA - PARANÁ
}

\begin{abstract}
Kauanna Uyara Devens ${ }^{1}$, Ana Paula Barroco Geraldini², Raíssa Martins Amadeo ${ }^{3}$, Marcelo Galeazzi Caxambu ${ }^{4}$, Pedro Henrique Jandreice Magnoni ${ }^{5}$
\end{abstract}

\section{RESUMO}

Epífitas são plantas que se utilizam de substratos arbóreos como apoio. São importantes na ciclagem de nutrientes, porém sensíveis a alterações, apresentando modificações conforme o grau de interferência sobre a estrutura das florestas. O presente estudo teve como principal objetivo realizar o levantamento das espécies de epífitas presentes na arborização da cidade de Luiziana - Paraná, bem como as espécies presentes apenas nas árvores de Ligustrum lucidum e Poincianella pluviosa. Todas as espécies de epífitas existentes nas árvores da arborização urbana foram amostradas e identificadas nas dependências do Herbário da Universidade Tecnológica Federal do Paraná Campus Campo Mourão (HCF). Foi relacionada a ocorrência de epífitas com o diâmetro a altura do peito (DAP) das espécies arbóreas predominantes. Os resultados mostraram que a maior parte das epífitas é holoepífita verdadeira, distribuindo-se em onze espécies dentro de cinco famílias, sendo Polypodiaceae e Bromeliaceae mais representativas na malha urbana. Das espécies de epífitas encontradas, $82 \%$ são espécies nativas, $18 \%$ espécies exóticas. Tanto para $L$. lucidum como para $P$. pluviosa, indivíduos de menor diâmetro a altura do peito $(1 \mathrm{a} 20 \mathrm{~cm})$ possuem poucas espécies de epífitas e poucos indivíduos ou estes estão ausentes.

Palavras-chave: Epifitismo; Ligustrum lucidum; Poincianella pluviosa.

\begin{abstract}
Epiphytes are plants that use arboreal substrates as support. They are important in nutrient cycling, but sensitive to changes, with modifications according to the degree of interference on the forest's structure. This study aimed to perform the listing of epiphytes on afforestation in the city of Luiziana - Paraná, as well as species found only in Ligustrum lucidum and Poincianella pluviosa trees. All the epiphytes species existing in the urban afforestation trees was sampled and identified on dependencies of Federal Tecnologic University of Paraná Herbarium (HCF). The occurrence of epiphytes was related to the diameter at breast height $(\mathrm{DBH})$ of the predominant tree species. The results showed that most of epiphytes are native, distributed into five families and eleven species, and Bromeliaceae and Polypodiaceae families were the groups with higher number of individuals. From the epiphytes found, $82 \%$ are native and $18 \%$ are exotics. Both $L$. lucidum and $P$. pluviosa individuals with small diameter at breast height $(1$ to $20 \mathrm{~cm}$ ) have less species of epiphytes and few individuals or they are missing.
\end{abstract}

Keywords: Epiphytism; Ligustrum lucidum; Poincianella pluviosa.

Recebido em 18.12.2015 e aceito em 23.02.2016

1 Graduanda em Engenharia Ambiental, Universidade Tecnológica Federal do Paraná, Rua Mato Grosso, 2139, ap. 207 - Campo Mourão-PR, kauanna.devens@hotmail.com

2 Graduanda em Engenharia Ambiental, Universidade Tecnológica Federal do Paraná, Rua Mato Grosso, 2139, ap. 208 - Campo Mourão-PR, anapaulabarroco1@gmail.com

3 Graduanda em Engenharia Ambiental, Universidade Tecnológica Federal do Paraná, Rua Mato Grosso, 2139, ap. 208 - Campo Mourão-PR, ra_amadeo@hotmail.com

4 Engenheiro Florestal, Dr., Professor no Departamento de Engenharia Ambiental na Universidade Tecnológica Federal do Paraná, Br 369, Km 0,5 (saída para Cascavel) bloco E - Campo Mourão-PR, mgcaxambu@yahoo.com.br

5 Graduando em Engenharia Ambiental, Universidade Tecnológica Federal do Paraná, Av. Capitão Índio Bandeira, 940, ap. 205 Campo Mourão-PR, pedrojandreice@gmail.com 


\section{INTRODUÇÃO}

Segundo Ritter et al. (2014) e Flórez e Montaño (2015), as epífitas são plantas que se fixam a um suporte pelo menos em uma fase de sua vida, porém sem se conectar ao substrato e não se utilizando diretamente de nutrientes das plantas em que se apoiam, denominadas de forófitos. Para Buzatto et al. (2008) a ocorrência das espécies epifíticas sobre os forófitos está relacionada ao tipo de substrato que estes proporcionam.

Estudos em várias regiões do globo têm demonstrado que a abundância, riqueza e estrutura das comunidades de epífitas vasculares, importantes elementos das florestas tropicais, mostram relevantes modificações de acordo com o grau de interferência sobre a estrutura das florestas (DETTKE; ORFRINI; MILANEZE-GUTIERRE, 2008; BATAGHIN et al., 2008).

Para Oliveira (2004) as epífitas, embora responsáveis por parte significativa da diversidade das florestas tropicais, são pouco estudadas em relação a outros componentes florestais, sendo que Oliveira e Arcela (2014) complementam esta ideia, ao afirmarem que ainda proporcionam grande diversidade ao ambiente, através de suas interações.

No Brasil, estudos referentes a composição florística e a distribuição espacial de epífitas vasculares são escassos, sendo Sul e Sudeste as regiões onde a maioria foi realizada (KERSTEN; KUNIYOSHI; RODERJAN, 2009).

No Paraná, pode-se citar o estudo de Dettke, Orfrini e Milaneze-Gutierre (2008) no Parque do Ingá, em Maringá, Geraldino, Caxambu e Souza (2010) em uma área de ecótono em Campo Mourão, Blum et al. (2011) na Serra da Prata, Bonnet et al. (2008) na planície de inundação do rio Iguaçu, além de Cervi e Borgo (2007) no Parque Nacional do Iguaçu. Sob mesma formação florestal do presente estudo, Fraga, Silva e Schmitt (2008) também realizaram levantamento de epífitas.

Nos levantamentos da flora epifítica no sul do Brasil, destacam-se algumas famílias de angiospermas (Bromeliaceae, Orchidaceae), estudadas por Perleberg e Tomkowski (2007), e de pteridófitas (Polypodiaceae) (ALVES et al., 2014).

Para epífitas na arborização urbana os trabalhos são ainda mais escassos e uma das poucas abordagens existentes foi conduzida por Ritter et al. (2014) sobre as epífitas existentes na malha urbana de Farol-PR.

Levando em consideração a carência de estudos sobre epifitismo em áreas urbanas no estado do Paraná, este trabalho teve como objetivo realizar um levantamento de espécies de epífitas que ocorrem na arborização na cidade de Luiziana - Paraná, como forma de contribuir para estudos relacionados sobre o assunto. 


\section{MATERIAL E MÉTODOS}

O estudo foi realizado em árvores da região urbana do município de Luiziana (Figura 1). O município pertence à mesorregião centro ocidental do Paraná (MEZZOMO; GHISSO; CAMPOS; 2014) e possui uma população estimada em 7.204 habitantes, sendo destes 4.350 residentes na região urbana e 2.854 habitantes na região rural (IBGE, 2015).

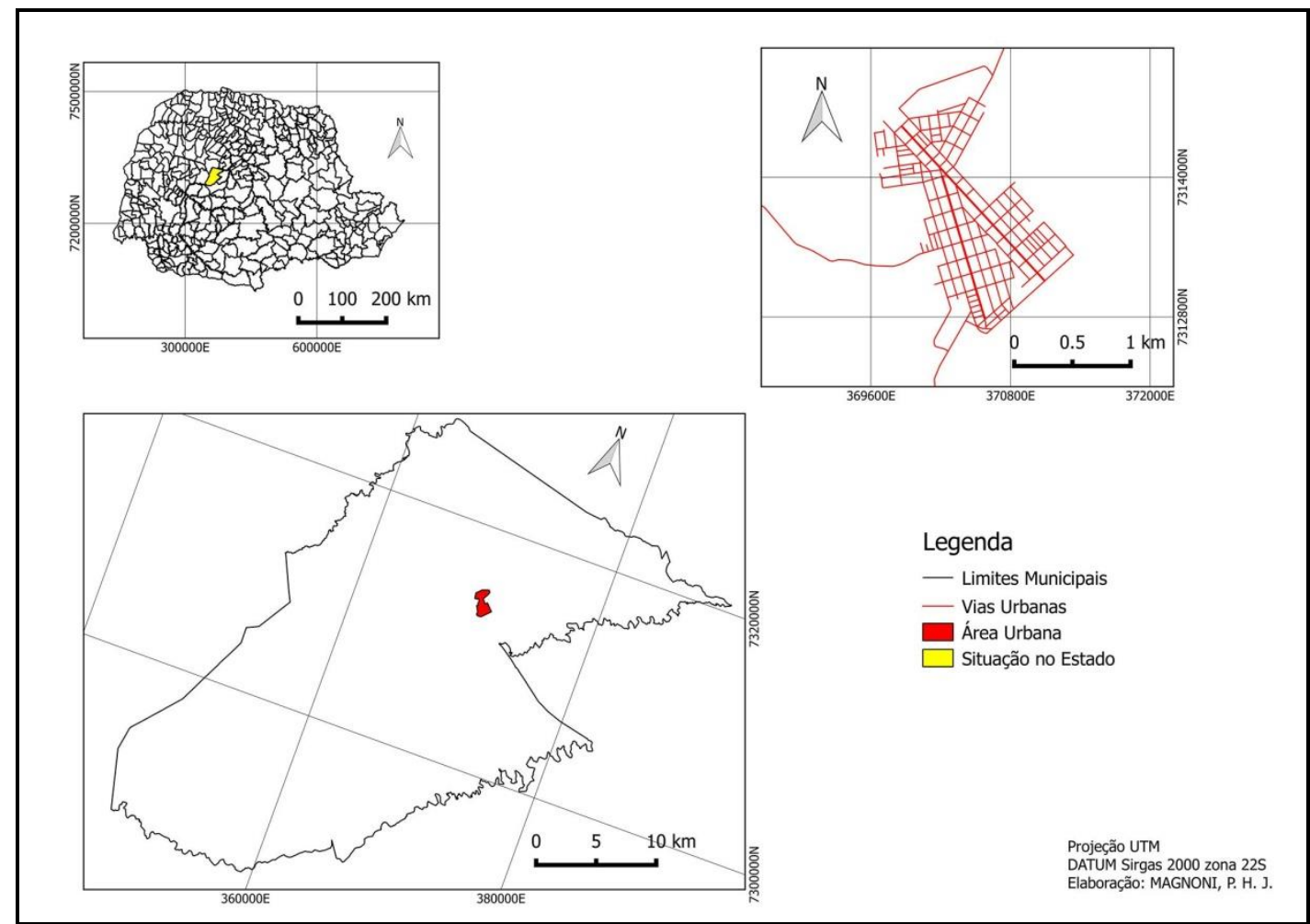

Figura 1. Localização do município de Luiziana no Estado do Paraná e na mesorregião Centro Ocidental Paranaense

Figure 1. Location of Luiziana's city in the state and Central West mesoregion of Paraná

De acordo com a classificação climática de Köppen-Geiger, o município possui clima subtropical úmido mesotérmico (Cfa), com temperatura média inferior a $18 \stackrel{\circ}{\circ} \mathrm{C}$ nos períodos mais frios, geadas pouco frequentes e médias acima de $22^{\circ} \mathrm{C}$ nos meses mais quentes com verões quentes e geadas pouco frequentes, com tendência de concentração das chuvas nos meses de verão, sem estação seca definida. Há tendência de concentração de chuvas nos meses de verão (dezembro, janeiro e fevereiro), ocorrendo no trimestre mais chuvoso a segunda maior faixa pluviométrica do estado do Paraná, com valores de 500 a $600 \mathrm{~mm}$ (IAPAR, 2009).

De acordo com Kersten, Kuniyoshi e Roderjan (2009), a área de estudo está inserida, predominantemente, no domínio da Floresta Ombrófila Mista Montana. Essa formação florestal 
tem como ochloespécie Araucaria angustifolia (Berol.) Kuntze, além de gêneros característicos como Drymis (Winteraceae) e Podocarpus (Podocarpaceae), além de Lauraceae e Myrtaceae entre outras.

Os solos encontrados nessa região são Latossolos (solos profundos, constituídos por materiais não minerais, em avançado processo de intemperização, alta permeabilidade, e com alto potencial para o uso agrícola) e Neossolos (solos pouco evoluídos, constituídos de material mineral ou orgânico pouco espesso, pouco potencial para uso agrícola, e forte susceptibilidade aos processos erosivos) (EMBRAPA, 2013).

O levantamento das epífitas foi conduzido entre os meses de setembro e outubro de 2015, onde foram registradas todas as espécies de epífitas ocorrentes nas árvores da arborização de Luiziana-PR com base nas técnicas usuais em levantamentos florísticos. Em seguida, o material foi levado para as dependências do Herbário da Universidade Tecnológica Federal do Paraná Campus Campo Mourão (HCF) onde foi então conduzida a identificação com base em bibliografia especializada e em comparação com o acervo do HCF. A classificação de famílias botânicas seguiu APG III (2009) para as Angiospermae e Smith et al. (2008) para as Pteridophytas. Para os epítetos específicos e seus respectivos autores foi utilizada a Lista da Flora do Brasil (2015).

As epífitas uma vez identificadas foram listadas e separadas em nativas ou exóticas segundo a Lista da Flora do Brasil (2015) e, na sequência, foi utilizada a classificação de Benzing (1990) para o tempo de permanência das epífitas no forófito: holoepífitas verdadeiras, facultativas ou acidentais e hemiepífitas primárias ou secundárias. Entende-se por holoepífitas verdadeiras, as plantas que nunca mantiveram contato com o solo em nenhuma fase de sua vida, facultativas como plantas que podem crescer normalmente sobre o solo ou em árvores, e acidentais como indivíduos que através de outros mecanismos naturais adquiriram características epifíticas; por fim, estabeleceu-se outra categoria ecológica, sendo esta denominada cultivada, categoria em que se enquadram as plantas que são colocadas na árvore pelo homem. Entende-se por hemiepífitas primárias espécies que germinam sobre os forófitos e posteriormente estabelecem contato com o solo através de raízes geotrópicas pendentes aos ramos e fustes, e hemiepífitas secundárias são espécies que germinam no solo posteriormente estabelecendo contato com um forófito, perdendo a ligação com o solo por meio da degeneração basal do sistema radical.

As síndromes de dispersão seguiram Pijl (1982), com as seguintes categorias:

a) Anemocóricos - quando os diásporos se apresentam alados, plumosos ou em forma de balão ou poeira;

b) Zoocóricos - quando os diásporos apresentam atrativos e/ou fontes de alimento, ou ainda, estruturas adesivas como ganchos, cerdas, espinhos, etc.; 
c) Autocóricos - quando não se encaixam nas duas categorias anteriores. Espécies barocóricas, ou seja, que apresentam dispersão por gravidade, e aquelas com dispersão explosiva.

Concomitantemente, foram inventariadas as três espécies arbóreas com maior ocorrência na arborização urbana de Luiziana, com o objetivo de procurar correlacionar a ocorrência de epífitas com o Diâmetro a Altura do Peito (DAP) do forófito. Os diâmetros foram obtidos através da Circunferência a Altura do Peito (CAP), medidos com uma fita métrica.

\section{RESULTADOS E DISCUSSÃO}

$\mathrm{Na}$ arborização urbana de Luiziana foram encontradas 11 espécies epifíticas, pertencentes a cinco famílias (Tabela 1). As famílias que apresentaram maior importância foram Bromeliaceae e Polypodiaceae, apresentado quatro espécies de cada, o que representa $72,7 \%$ do total das epífitas encontradas no município. Estes resultados assemelham-se àqueles encontrados por Ritter et al. (2014), em um estudo realizado na cidade de Farol Paraná, onde foram encontradas 10 espécies distribuídas em sete famílias distintas, com maior ocorrência de Bromeliaceae e Polypodiaceae.

Tabela 1. Lista de epífitas encontradas na arborização urbana de Luiziana - PR

Table 1. List of epiphytes found in urban afforestation of Luiziana - PR

\begin{tabular}{llcc}
\hline Família & Espécie & $\begin{array}{c}\text { Categorias } \\
\text { Ecológicas }\end{array}$ & $\begin{array}{c}\text { Síndrome de } \\
\text { dispersão }\end{array}$ \\
\hline Araceae & Philodendron bipinnatifidum Schott ex Endlicher & HMP & ZOO \\
\hline \multirow{2}{*}{ Bromeliaceae } & Aechmea distichanta Lem. & HLF & ANE \\
& Tillandsia pohliana Mez & HLV & ANE \\
& Tillandsia recurvata (L.) L. & HLV & ANE \\
& Vriesea friburgensis Mez & HLV & ANE \\
\hline Cactaceae & Rhipsalis cereuscula Haw. & HLV & ZOO \\
\hline Orchidaceæ & Dendrobium nobile Lindl. & CUL* & ANE \\
\hline Polypodiaceae & Microgramma squamulosa (Kaulf.) dela Sota & HLV & ANE \\
& Platycerium bifurcatum C. Chr. & CUL* & ANE \\
& Pleopeltis minima (Bory) J. Prado \& R.Y. Hirai & HLV & ANE \\
& Pleopeltis pleopeltifolia (Raddi) Alston & HLV & ANE \\
\hline
\end{tabular}

Notas: Categorias Ecológicas (CE): HLV - holoepífita verdadeira, HLF - holoepífita facultativa, HLA - holoepífita acidental, HMP - hemiepífita primária, HMS - hemiepífita secundária;Síndromes de dispersão (SD): ANE anemocoria, AUT - autocoria, ZOO - zoocoria, CUL: Cultivada e exótica; 
Com relação às categorias ecológicas, sete epífitas ou $63,63 \%$ foram classificadas como holoepífitas verdadeiras, representadas pelas famílias Bromeliaceae, Cactaceae e Polypodiaceae. A espécie da família Aracaceae, por outro lado, foi considerada hemiepífita primária com apenas um indivíduo ou 9,09\% e a espécie da família Bromeliaceae, também com um indivíduo ou 9,09\%, considerada holoepífita facultativa. Foram encontradas duas espécies, com um indivíduo cada, classificadas como cultivadas, com 18,18\%. Esses dados também se assemelham aos de Ritter et al. (2014), que registraram 70\% de indivíduos classificados como holoepifitas verdadeiras, seguidos de $20 \%$ de holoepifitas acidentais e $10 \%$ de espécies cultivadas.

Comparando os dados de arborização urbana com os estudos realizados em remanescentes florestais por Geraldino, Caxambu e Souza (2010) e Dettke, Orfrini e MilanezeGutierre (2008), ainda assim há predominância de holoepifitas verdadeiras, representando $83,87 \%$ e $83,33 \%$ respectivamente.

Entre as síndromes de dispersão, destaca-se a anemocoria, representada por nove espécies $(81,8 \%)$ de epífitas da arborização do município, seguida pela zoocoria com duas espécies (18,2\%). Esta distribuição também foi observada no trabalho de Ritter et al. (2014), onde os autores obtiveram 10 espécies de epífitas, das quais $80 \%$ foram anemocóricas e $20 \%$ zoocóricas. Já em áreas de fragmentos florestais, com condições ambientais e ecológicas distintas, Dettke, Orfrini e Milaneze-Gutierre (2008) encontraram 60\% de espécies zoocóricas e $40 \%$ de zoocóricas (desconsiderando as espécies da família Viscaceae, porque são hemiparasitas) enquanto que Geraldino, Caxambu e Souza (2010) obtiveram 66,13\% de espécies anemocóricas, 32,26\% de zoocóricas e 1,61\% de autocóricas.

Os resultados obtidos para síndromes de dispersão neste trabalho podem indicar que espécies anemocóricas na arborização urbana parecem estar sendo beneficiadas em detrimento das zoocóricas. Isto provavelmente se deve à falta de dispersores na malha urbana, aliado à baixa quantidade de matrizes de epífitas zoocóricas encontradas em Luiziana, que também foi observado no trabalho de Ritter et al. (2014). Entretanto são necessárias novas investigações que possam comprovar ou refutar esta hipótese.

No caso de Rhipsalis cereuscula Haw, existem evidências de que a planta, embora nativa e de ocorrência natural no município, ocorreu em Citrus spp., seu forófito, por ação antrópica, através do cultivo.

Outra possibilidade que se aventa, é de que espécies da família Polypodiaceae e de Bromeliaceae, principalmente Tillandsia spp., sejam as principais plantas vasculares colonizadoras de árvores na arborização urbana, o que pode explicar a sua predominância em relação às demais neste estudo, bem como no de Ritter et al. (2014). 
As espécies da família Orchidaceae, por outro lado, são plantas que necessitam de condições ambientais mais favoráveis para a sua instalação e manutenção. Fabricante, Andrade e Marques (2006) ainda salientam que uma área urbana antropizada, distante de áreas nativas, apresenta grandes obstáculos à ocorrência das mesmas (microclima desfavorável, baixa capilaridade gênica, baixa diversidade de árvores, dentre outras).

Como as árvores do município apresentam diversas classes de DAP (Tabela 2 e 3), variando de $1 \mathrm{a} 60 \mathrm{~cm}$, aliado ao fato que as árvores com diâmetros variando de 40,1 a $60 \mathrm{~cm}$, tiveram seus indivíduos em quase sua totalidade sofrido poda drástica, o que implica na retirada de galhos com epífitas instaladas e alteração de condições microclimáticas como luz, umidade e temperatura, tornando o ambiente inóspito para a instalação de epífitas.

Adicionalmente, foi verificado através de levantamento de indivíduos que três espécies arbóreas são as mais frequentes para Luiziana, sendo: Ligustrum lucidum W.T. Aiton. (ligustro), Poincianella pluviosa var. peltophoroides (Benth.) L.P. Queiroz (sibibiruna), e Schinus molle L.(chorão), com um total de 612 indivíduos.

Do total de árvores avaliadas, 138 indivíduos foram de S. molle, que possuía somente um espécime de Dendrobium nobile Lindl, que se trata de uma planta cultivada. Nas outras duas espécies arbóreas levantadas, L. lucidum e P. pluviosa, com respectivamente, 271 indivíduos e 203 indivíduos, apresentaram epífitas em 183 árvores (67,4\%) para L. Lucidum e 119 árvores (58,9\%) de P. pluviosa.

Para L. lucidum, isoladamente, foram encontradas seis espécies de epífitas pertencentes a três famílias botânicas, sendo que a família mais representativa em espécies e frequência foi Polypodiaceae.

Houve aumento inicial de espécies das classes de diâmetros menores para as maiores, chegando ao maior número de espécies, cinco espécies, nas classes de diâmetro a altura do peito de 20,1 a $30 \mathrm{~cm}$ e de 30,1 a $40 \mathrm{~cm}$ (Tabela 2). Após estas classes, houve uma queda no número de espécies para L. lucidum nas duas últimas classes de diâmetro, que está, muito provavelmente, relacionado às podas drásticas sofridas pela maioria dos indivíduos de grande porte, o que também ocorreu no trabalho de Ritter et al. (2014) para L. lucidum. Argumenta-se que árvores de grande porte teriam maior tempo para a colonização epifítica devido a maior exposição à chuva de propágulos.

Para $P$. pluviosa, estes dados foram análogos, entretanto, nas duas primeiras classes de diâmetro, não houve a ocorrência de epífitas, sendo que a colonização só ocorreu na terceira classe, ou seja, a partir de 20,1 a $30 \mathrm{~cm}$ (Tabela 3). Isto provavelmente se deve ao fato de $P$. pluviosa ser uma espécie semicaducifólia, o que pode influenciar o microclima para as epífitas, mas estudos neste sentido são necessários para testar esta hipótese. Foi notória a 
presença de podas drásticas, assim como em L. lucidum, nos indivíduos de maior diâmetro, ocorrendo, consequentemente, uma diminuição no número de espécies de epífitas.

Tabela 2. Relação entre diâmetro da altura do peito (DAP) e a presença de epífitas em Ligustrum lucidum W.T. Aiton (Oleaceae)

Table 2. Relation between diameter at breast height (DBH) and the presence of epiphytes in Ligustrum lucidum W.T. Aiton (Oleaceae)

\begin{tabular}{|c|c|}
\hline DAP (cm) & Espécie \\
\hline $1-10$ & $\begin{array}{l}\text { Pleopeltis pleopeltifolia (Raddi) Alston } \\
\text { Pleopeltis minima (Bory) J. Prado \& R.Y. Hirai }\end{array}$ \\
\hline $10,1-20$ & $\begin{array}{l}\text { Pleopeltis pleopeltifolia (Raddi) Alston } \\
\text { Microgramma squamulosa (Kaulf.) dela Sota } \\
\text { Pleopeltis minima (Bory) J. Prado \& R.Y. Hirai }\end{array}$ \\
\hline $20,1-30$ & $\begin{array}{l}\text { Pleopeltis pleopeltifolia (Raddi) Alston } \\
\text { Philodendron bipinnatifidum Schott ex Endlicher } \\
\text { Microgramma squamulosa (Kaulf.) dela Sota } \\
\text { Pleopeltis minima(Bory) J. Prado \& R.Y. Hirai } \\
\text { Platycerium bifurcatum C. Chr. }\end{array}$ \\
\hline $30,1-40$ & $\begin{array}{l}\text { Pleopeltis pleopeltifolia (Raddi) Alston } \\
\text { Microgramma squamulosa (Kaulf.) dela Sota } \\
\text { Pleopeltis minima (Bory) J. Prado \& R.Y. Hirai } \\
\text { Platycerium bifurcatum C. Chr. } \\
\text { Tillandsia pohliana Mez }\end{array}$ \\
\hline $40,1-50$ & $\begin{array}{l}\text { Pleopeltis pleopeltifolia (Raddi) Alston } \\
\text { Tillandsia pohliana Mez } \\
\text { Pleopeltis minima (Bory) J. Prado \& R.Y. Hirai }\end{array}$ \\
\hline $50,1-60$ & Pleopeltis pleopeltifolia (Raddi) Alston \\
\hline
\end{tabular}

Tabela 3. Relação entre diâmetro da altura do peito (DAP) e a presença de epífitas em Poincianella plunviosa var. peltophoroides (Benth.) L.P. Queiroz (Fabaceae)

Table 3. Relation between diameter at breast height $(\mathrm{DBH})$ and the presence of epiphytes in Poincianella pluviosa var. peltophoroides (Benth.) L.P. Queiroz (Fabaceae)

\begin{tabular}{cl}
\hline DAP $(\mathbf{c m})$ & Espécie \\
\hline $\mathbf{1 - 1 0}$ & Ausência de epífitas \\
\hline $\mathbf{1 0 , 1 - 2 0}$ & Ausência de epífitas \\
\hline \multirow{2}{20,1-30}{} & Tillandsia recurvata (L.) L. \\
& Aechmea distichanta Lem. \\
\hline \multirow{3}{*}{$\mathbf{3 0 , 1 - 4 0}$} & Vriesea friburgensis Mez \\
& Tillandsia recurvata(L.) L. \\
& Dendrobium nobile Lindl. \\
\hline $\mathbf{4 0 , 1 - 5 0}$ & Tillandsia recurvata (L.) L. \\
\hline $\mathbf{5 0 , 1 - 6 0}$ & Ausência de epífitas \\
\hline
\end{tabular}




\section{CONCLUSÃO}

Com base no levantamento realizado das epífitas ocorrentes na arborização urbana de Luiziana-PR, foram encontradas 11 espécies, distribuídas em cinco famílias, com predominância de Bromeliaceae e Polypodiaceae, apresentando quatro espécies de cada, o que representa no total $72,7 \%$ das epífitas encontradas no município.

Das espécies de epífitas encontradas, 82\% são espécies nativas e 18\% exóticas. Tanto para L. Iucidum como para $P$. pluviosa, indivíduos de menor diâmetro a altura do peito possuem poucas espécies de epífitas e poucos indivíduos ou estes estão ausentes. Parece haver uma relação entre poda drástica e a ausência de epífitas em árvores de maior diâmetro, sendo fortemente recomendável que se conduzam estudos que possam elucidar esta situação.

Observou-se a predominância de holoepífitas verdadeiras, distribuídas em sete espécies ou 63,63\%, representadas pelas famílias Bromeliaceae, Cactaceae e Polypodiaceae.

Quanto à síndrome de dispersão, destaca-se a anemocoria, representada por nove espécies ou $81,8 \%$ das espécies de epífitas da arborização do município, seguida pela zoocoria com duas espécies ou $18,2 \%$ de ocorrência. Esses dados podem indicar a falta de dispersores na malha urbana, havendo o beneficiamento de espécies anemocóricas na arborização urbana. Por fim, destaca-se a importância de novos estudos sobre epifitismo na arborização urbana, visto que as referências sobre a mesma são escassas.

\section{REFERÊNCIAS}

ALVES, O. E. M.; BRUN, C.; FORNO, R. S. D.; ESSI, L. Levantamento de espécies epífitas vasculares da zona urbana do município de Palmeiras das Missões, Rio Grande do Sul, Brasil. Ciência e Natura, Santa Maria, v. 36, p. 268 - 276, 2014.

BATAGHIN, F. A; FIORI, A; TOPPA, R. H. Efeito de borda sobre epífitos vasculares em floresta ombrófila mista, Rio Grande do Sul, Brasil. O Mundo da Saúde, São Paulo: set, 2008.

BENZING, D. H. Vascular epiphytes. Cambridge: Cambridge University Press, 1990. 371p.

BLUM, C. T.; RODERJAN, C. V.; GALVÃO, F. Composição florística e distribuição altitudinal de epífitas vasculares da Floresta Ombrófila Densa na Serra da Prata, Morretes, Paraná, Brasil. Biota Neotropica, Campinas, v. 11, n. 4, p. 141-159, 2011.

BONNET, A.; CURCIO, G.R.; LAVORANTI, O.J.; BARDDAL, M. L.; RODERJAN, C. V. Relações de bromeliáceas epifíticas com fatores ambientais em planícies de inundação do rio Iguaçu, Paraná, Brasil. Floresta, Curitiba, v. 40, n.1, p. 193-208, 2010. 
BUZATTO, C. R.; SEVERO, B. M. A.; WAECHTER, J. L. Composição florística e distribuição ecológica de epífitos vasculares na Floresta Nacional de Passo Fundo, Rio Grande do Sul, Porto Alegre. Iheringia, Série. Botânica, Porto Alegre, v. 63, p. 231 - 239, 2008.

CERVI, A.C.; BORGO, M. Epífitos vasculares no Parque Nacional do Iguaçu, Paraná Levantamento preliminar. Fontqueria, Madrid, v 55, p. 415-422, 2007.

DETTKE, G. A.; ORFRINI, A. C.; MILANEZE-GUTIERRE, M. A. Composição florística e distribuição de epífitas vasculares em um remanescente alterado de Floresta Estacional Semidecidual no Paraná, Brasil. Rodriguésia, Rio de Janeiro, v. 59, n. 4, p. 859-872, 2008.

EMPRESA BRASIEIRA DE PESQUISA AGROPECUÁRIA - EMBRAPA. 2013. Sistema Brasileiro de Classificação de Solos. Embrapa Solos, Rio de Janeiro, 2013.

FABRICANTE, J. R.; ANDRADE, L. A.; MARQUES, F. J. Componente epifítico vascular ocorrente em árvores urbanas. Cerne, Lavras, v. 12, n. 4, p. 399-405, 2006.

FLÓREZ, C. B. R.; MONTAÑO, L. R. S. Estructura espacial de epífitas vasculares en dos localidades de bosque altoandino, pamplona, Colômbia. Caldásia, Bogotá, v. 37, n.1, 2015.

FRAGA, L.L.; SILVA, L.B.; SCHMITT, J.L. Composição e distribuição vertical de pteridófitas epifíticas sobre Dicksonia sellowiana Hook. (Dicksoniaceae), em floresta ombrófila mista no sul do Brasil. Biota Neotropica, Campinas, v.8, n. 4, 2008.

GERALDINO, H. C. L.; CAXAMBÚ, M. G.; SOUZA, D. C. Composição florística e estrutura da comunidade de epífitas vasculares em uma área de ecótono em Campo Mourão, PR, Brasil.

Acta Botânica Brasílica, São Paulo, v. 24, n. 2, p. 469-482, 2010.

INSTITUTO BRASILEIRO DE GEOGRAFIA E ESTATÍSICA - IBGE, 2015. População. Disponível em: <http://cidades.ibge.gov.br/xtras/perfil.php?lang=\&codmun=411373>. Acesso em: 30 nov. 2015

INSTITUTO AGRONÔMICO DO PARANÁ - IAPAR, 2009. Cartas Climáticas do Paraná. Londrina, Paraná. Disponível em: Acesso em http://www.iapar.br/modules/conteudo/conteudo .php?conteudo=677: 15 nov. 2015.

KERSTEN, R. A.; KUNIYOSHI, Y. S. Conservação das Florestas na Bacia do Alto Iguaçu, Paraná - Avaliação da comunidade de epífitas vasculares em diferentes estágios serais. Floresta, Curitiba, Paraná, v. 39, n. 1, p. 51 - 66, 2009.

KERSTEN, R. A.; KUNIYOSHI, Y. S.; RODERJAN, C. V. Epífitas vasculares em duas formações ribeirinhas adjacentes na bacia do rio Iguaçu - Terceiro Planalto Paranaense. Iheringia: Série Botânica, Porto Alegre, v.64, n.1, p.33-43, 2009.

Lista de Espécies da Flora do Brasil. Jardim Botânico do Rio de Janeiro. Disponível em:<http://floradobrasil.jbrj.gov.br/>. Acesso em: 15 Dez. 2015.

MEZZOMO, M. M.; GHISSO, K. W.; CAMPOS, D. V.; Caracterização geoecológica como subsídio para estudos ambientais em RPPNS: estudos de casos no Paraná. Revista Árvore, Viçosa-MG, v.38, n.5, p.907-917, 2014.

OLIVEIRA, R. R. Importância das bromélias epifíticas na ciclagem de nutrientes da Floresta Atlântica. Acta Botanica Brasilica, São Paulo, v.18, n. 2, p.793-799, 2004. 
OLIVEIRA, R. P.; ARCELA, V. Distribuição vertical e valor de importância das epífitas vasculares da reserva biológica do Guará, Brasília, DF. Heringeriana, Brasília, v.8, n. 1, p. 20 31, 2014.

PERLEBERG, T. D.; TOMKOWSKI, S P. B. P. Bromeliaceae e Orchidaceae Epífitas nas Trilhas do Ecocamping Municipal de Pelotas, RS, Brasil. Revista Brasileira de Biociências, Porto Alegre, v. 5, p. 720- 722, 2007.

PIJL, L. V. Principles of dispersal in higherplants. $3^{\circ}$ Ed. Berlin: Springer-Verlag, 1982.

RITTER, C. M.; SANTOS, F. R.; CRESPÃO, L. M. P.; ARDENGUI, T. C.; CAXAMBÚ, M. G. Levantamento de epífitas presentes na arborização urbana no município de Farol, PR, Brasil. Revista da Sociedade Brasileira de Arborização urbana, Piracicaba - SP, v.9, n.3, p 18-28, 2014.

SMITH A.R., PRYER, K.M., SCHUETTPELZ, E., KORALL, P., SCHNEIDER, H. and WOLF, P.G. Fern Classification. In RANKER, TA. and HAUFLER, CH. (Eds.). The Biology and Evolution of Ferns and Lycophytes. Cambridge: Cambridge University Press, p. 417-467, 2008. 